\title{
ASPECTOS DA RESPONSABILIDADE CIVIL POR FATO DE TERCEIRO NO DIREITO ROMANO*
}

\author{
Dárcio Roberto Martins Rodrigues \\ Professor Doutor do Departamento de Direito Civil da \\ Faculdade de Direito da Universidade de São Paulo
}

\begin{abstract}
Resumo:
Em diversas situações uma pessoa é considerada responsável por danos causados por um terceiro. Os juristas romanos, como era seu hábito, não desenvolveram uma doutrina geral acerca de tal responsabilidade vicária, a qual eles apenas tratavam caso a caso. Por conseqüência, em vez de um tratamento geral e sistemático da matéria, eles antes conceberam várias soluções diferentes, cada uma aplicável unicamente a situações muito específicas, quer no campo dos contratos, quer no dos atos ilicitos (e.g. receptum, actiones adiecticiae qualitatis, actiones noxales, quasi-delicta, etc.). Casos há, todavia, que não se podem subsumir em nenhuma dessas soluções específicas, por exemplo se um empregado livre e independente, em vez de um escravo ou membro da família, causasse dano à outra parte em um contrato avençado pelo empregador. O presente ensaio apresenta um estudo exegético de diversos casos assim, em uma tentativa de compreender as tendências da jurisprudência romana nesse tocante.
\end{abstract}

\begin{abstract}
:
In a number of situations a person is held liable for harm brought about by another. Roman jurists, as usual, did not develop a general doctrine on such vicarious liability, which they only dealt with on a case-by-case basis. Accordingly, instead of a general and systematic treatment of the matter they rather devised several diverse solutions, each one applicable only to very specific situations, either in the field of contract or of torts (e.g. receptum, actiones
\end{abstract}

* O prescnte cnsaio ć uma breve sinopsc de minha tesc de doutorado, na qual cstas idćias são desenvolvidas amplamentc $\mathrm{cm}$ um trabalho excgético mais aprofundado c com complcta indicação bibliográfica. Meus agradecimentos ao estimado Prof. Andreas Wacke $\mathrm{c}$ ao Institut fïr rö̈misches Recht der Universität zu Köln (Alcmanha), onde foi desenvolvida a maior parte da pesquisa para csta obra. 
adiecticiae qualitatis, actiones noxales, the quasi-delicta, etc.). There are cases, however, which cannot be subsumed into any of those specific, ready-made solutions, for instance if a free and independent employee, instead of a slave or member of the family, should cause harm to the other part in a contract entered into by the employer. This essay, which is but a brief synopsis of a much more detailed dissertation of doctorate, presents an exegetic study of several such cases, in an attempt to understand the tendencies of Roman jurisprudence in that respect.

Unitermos: Responsabilidade, contrato, terceiro, romano.

\section{Exposição do Problema}

No âmbito do Direito Privado, entendemos por responsabilidade a sujeição patrimonial do devedor ao credor para a satisfação de um crédito.' Como regra, toca a cada um a responsabilidade civil pelos seus próprios atos, quer na esfera contratual, quer na delitual. Casos há, entretanto, em que o Direito atribui a uma pessoa o dever de responder por atos praticados por uma outra. Dado que tais casos refogem à regra geral, cumpre delimitar com exatidão os critérios de determinação e a abrangência dessa responsabilidade vicária.

No Direito Romano todavia não encontramos, como já é habitual, uma solução geral e uniforme, com critérios fixos e determinados, para fazer face ao

1. Cf. Brinz, Lehrbuch der Pandekten, Erlangen, Deichert, 2 ed., 1879, v. 2, \$207, p. 2 : "Haftung nennen wir dic Thatsache, daß ctwas, cine Person oder Sachc, jemandem (Gläubiger) zur Satisfaction fuir ctwas zu dicnen bestimmt ist". Deve-se a Brinz a difcrenciação cntre os conccitos de Schuld (ou debitum) c Haftung (ou obligatio), sendo aquela o dever jurídico de cumprir uma prestação e csta a sujcição do devedor à invasão do scu patrimônio ("das Unterworfenscin unter dic Zugriffsgcwalt", cf. KASER, Lehrb. [=Römisches Privatecht - Ein Studienbuch, 16 cd., Münclıcn, Bcck, 1992]. 32 ll 5, p. 153) por parte do credor (sobrc o assunto ver também de Brinz, Der Begriff' obligatio, in Zeitschrift fiir dlas privat und öffentliche Recht der Gegenwart [Grïnhüts Zeitschrift], v. I (1874), pp. II-40). A doutrina atual considcra debitum c obligatio termos técnicos sinônimos, como tais cmpregados nas fontes romanas (cf. Kunkcl/ Honscll, Römisches Recht, Berlin/Hcidclbcrg, Springer-Verlag, 4 cd., 1987, \$ 87, p. 213; c nt. 6, com indicaçõcs bibliográficas bastante completas sobre cste ponto). Pensamos, porćm, com VOCI (Le obbligazioni romane, Milano, Giuffrè, 1969, p.26) quic, conquanto não corrcsponda ao pensamento romano, a distinção ainda ć provcitosa, já não como tentativa de definir a cstrutura da relação obrigacional romana na realidade da sua cvolução histórica, mas apenas como csquema classificatório útil para a comprecnsão dos vários aspectos c fases da rclação obrigacional. A questão toda ć, no cntanto, de somenos rclevância para as finalidades deste nosso estudo, c, no que presentemente interessa, basta-nos a definição que adotamos acima. 
problema. As fontes nos oferecem, é verdade, uma grande variedade de situações em que se caracterizam de modo inequívoco casos de responsabilidade civil por fato de terceiros, mas um tratamento sistemático do assunto não foi jamais intentado pelos juristas romanos. Como era bem de sua índole, apresentavam as soluções para tais situações de maneira casuística, sem a preocupação de erigi-las em doutrina. Assoma ainda o fato de que, em meio à congérie de decisões díspares que se podem respigar nos textos das fontes, algumas se referem a institutos antigos do ius civile, enquanto outras foram trazidas por ações pretorianas bem específicas, e não é simples o trabalho do estudioso que procure delas depreender os princípios maiores que norteavam a iurisprudentia romana nessa matéria.

Tentando organizar esses casos em um esquema global mais compreensível - e apenas com finalidades heurísticas, sem pretender afirmar que um semelhante esquema corresponda de fato a uma noção consciente dos jurisconsultos romanos - poderíamos, em um primeiro momento, adotar como summa divisio a classificação entre responsabilidade contratual e responsabilidade extracontratual, ou seja, conforme ela se origine ou não de uma relação contratual entre o lesado e a pessoa a quem incumbe responder pelo dano provocado por outrem.

No campo extracontratual, o caso típico no direito romano é o da responsabilidade do paterfamilias pelos delitos privados cometidos por pessoas sob a sua potestas. Em tal hipótese encontrava aplicação o princípio da chamada responsabilidade noxal, resultante das actiones noxales propostas contra o detentor da potestas sobre aquele que foi o autor do delito. No contexto de que ora tratamos, entretanto, a responsabilidade noxal representa um caso à parte. É um instituto singular, com princípios e regras que lhe são próprios, os quais têm sido exaustivamente estudados pela doutrina romanística.

Ainda no campo extracontratual temos a figura dos quase-delitos positum et suspensum e effusum et deiectum. A responsabilidade era sempre atribuída ao habitator, ao chefe da casa, independentemente de quem tivesse sido o causador do fato o que significa que ele respondia também pelo fato de terceiros. Trata-se aqui, porém, de ações honorárias in factum, muito específicas, e pouco se prestam ao resultado pretendido neste nosso estudo, de caráter mais amplo. Não é possível delas inferir princípios que se possam estender de modo generalizado para outros casos, de obrigações originárias de outros fatos geradores.

Passando para a esfera contratual, há que se fazer antes de tudo uma distinção entre a responsabilidade do paterfamilias em razão de negócios celebrados 
por pessoas submetidas à sua potestas e aquela resultante de contratos por ele pessoalmente celebrados, mas dos quais resultaram danos à outra parte contratante, imputáveis a pessoas submetidas à sua esfera de controle. A primeira hipótese - negócios celebrados por escravos ou filii familias - nos conduziria ao exame das chamadas actiones adiecticiae qualitatis, as quais, porém, não constituem chamadas actiones adiecticiae qualitatis, as quais, porém, não constituem propriamente um caso de responsabilidade civil por fato de terceiro no sentido que aqui nos interessa, mas antes uma forma embrionária de representação direta do paterfamilias pelas pessoas submetidas ao seu poder. ${ }^{2}$

Mais interessante para nós é o segundo caso mencionado; nele, o escravo ou alieni iuris não é parte no negócio, mas é o causador do prejuízo para a outra parte contratante. Em muitos casos, o agente causador do dano é empregado pelo paterfamilias como auxiliar para o cumprimento da prestação, resultando o dano da conduta negligente ou dolosa desse auxiliar. ${ }^{3}$ Outras vezes o terceiro não está diretamente envolvido no cumprimento da prestação, mas, atuando cotidianamente na esfera de influência do contratante, pode vir a danificar bens pertencentes à outra parte no negócio. ${ }^{4}$ Isso sói acontecer amiúde sobretudo nos contratos em que uma das partes recebe sob sua guarda uma coisa pertencente à outra, tais como nos contratos reais (penhor, comodato, depósito) e também na locação.

Tampouco aqui se encontra nas fontes um tratamento uniforme do problema. Temos, por um lado, e especificamente para os contratos de hotelaria e transporte, a figura do receptum, que é também um caso particularíssimo, porquanto resulta não de um contrato formal do ius civile, mas de um acordo ou pactum especial tutelado por uma actio in factum (usualmente chamado, em linguagem não-técnica, de pactum praetorium). ${ }^{5}$

Excluída a situação especial do receptum, temos de resto as normas gerais

2. Sob csse ponto de vista, ver Wacke, Die adjektizischen Klagen im Überblick - Von der Reedecrund Betriebsklage zu' direkten Stellvertretung, SZ[=Zcitschrift der Savigny-Stiftung für Rechtsgeschichte] 111 (1994), pp. 280-362.

3. A doutrina alcmã, com sua habitual precisão, designa tal sorte de preposto com o termo especifico Erfüllungsgehilfe, cf. $\$ 278$ do BGB.

4. Consoantc o que a doutrina alcmã denomina Verrichtumgsgehilfe, cf. $\$ 831$ BGB.

5. Um cstudo mais detalhado do instituto do receptum no âmbito da responsabilidade por fato de tercciro scrá objeto de um capítulo especial de nossa tesc de livrc-docência, atualmente cm fasc de conclusão. 
da responsabilidade contratual. Também a esse respeito muitas questões delicadas se nos deparam. Em primeiro lugar, é mister indagar, no que tange às fontes romanas, em que medida os diversos fragmentos que respeitam ao nosso tema realmente apontam para uma responsabilidade civil por fato de terceiro propriamente dita, ou para um simples dever geral de garantia imposto ao devedor perante o credor, em cujo contexto o fato de terceiro figuraria apenas como um casus minor, um caso fortuito, pelo qual o devedor deve responder. Essa indagação é relevante, sobretudo, no terreno da chamada responsabilidade por custodia, sobre cuja natureza e extensão ainda muito se contende. ${ }^{6}$ É o caso, por exemplo, do proprietário de uma lavanderia (fullo): sabemos pelas fontes que ele responde pelos danos causados pelos seus auxiliares, mas não se deve perder de vista que ele respondia, da mesma forma, até mesmo pela ação de roedores que esburacassem as vestimentas entregues aos seus serviços. ${ }^{7}$ Vê-se, pois, que, ao menos nesse caso específico, não se trata de verdadeira responsabilidade por fato de terceiro, mas antes um dever de garantia ou uma certa assunção do periculum, isto é, dos riscos da coisa entregue à sua guarda.

De outra parte, cabe ainda questionar de que modo se fundamentava essa responsabilidade por fato de terceiro, quando realmente a havia. Seria ela caracterizada como um dever incondicional de responder pela conduta alheia, independentemente de culpa própria do responsável (nos moldes, por exemplo, do $\S$ 278 do BGB alemão)? Em muitas passagens das fontes localizam-se expressões que, ao contrário, parecem fundamentá-la na conduta pessoal do devedor, que teria sido descuidado na seleção das pessoas às quais cometeu a execução de uma tarefa. Dizem então os jurisconsultos romanos que ele é responsável "quod imprudenter eum elegerit" (Paul. lib. 9 ad ed. D.3,5,20,3), "si minus idoneis hominibus eam commisit" (Paul. lib. 21 ad ed. D. 6,1,16,1), ou "si neglegens in eligendis ministeriis fuit" (Ulp. lib. 18 ad ed. D.9,2,27,9), ou ainda outras expressões do mesmo teor. Isso conduziu a doutrina romanística a formular a teoria da culpa in eligendo (expressão que, contudo, não aparece como terminus technicus nas fontes), que em última análise nada mais seria do que uma modalidade de responsabilidade por fato próprio.

6. Sem pretensão alguma de solucionar tais questões ou inovar as pesquisas nessc campo tão cspinhoso, tencionamos nào obstante discorrer mais longamente sobre o problema da custódia c sua inscrção no contcxto ora discutido, mas farcmos isso $\mathrm{cm}$ um outro capítulo cspccial de nossa tese de livre-docência, a ser concluída brevemente.

7. Ulp. D.19.2.13.6 : "Si fullo vestimenta polienda acciperit, eaque mures roserint, ex locato tenetu" $(\ldots)$. 
A questão é que a textualidade desses fragmentos das fontes não deixa claro se essa culpa in eligendo era realmente o fundamento jurídico do dever de responder, ou se mera justificativa moral ou teórica para o reconhecimento jurídico desse dever. Em outros termos: era a culpa do comitente um verdadeiro pressuposto da responsabilidade (e em tal caso se lhe abriria a possibilidade de exculpação, bastandolhe demonstrar não ter havido desídia de sua parte na escolha de seus ajudantes), ou apenas uma conclusão inelutável, decorrente da simples ocorrência da falta cometida pelo subordinado (e então poderíamos falar de uma culpa fictícia, ou, antes, presumida iuris et de iure)?

Em vista do que até aqui expusemos, é possível esboçar o seguinte esquema, apto a sumariar com maior clareza a ordem das idéias que vimos expondo:

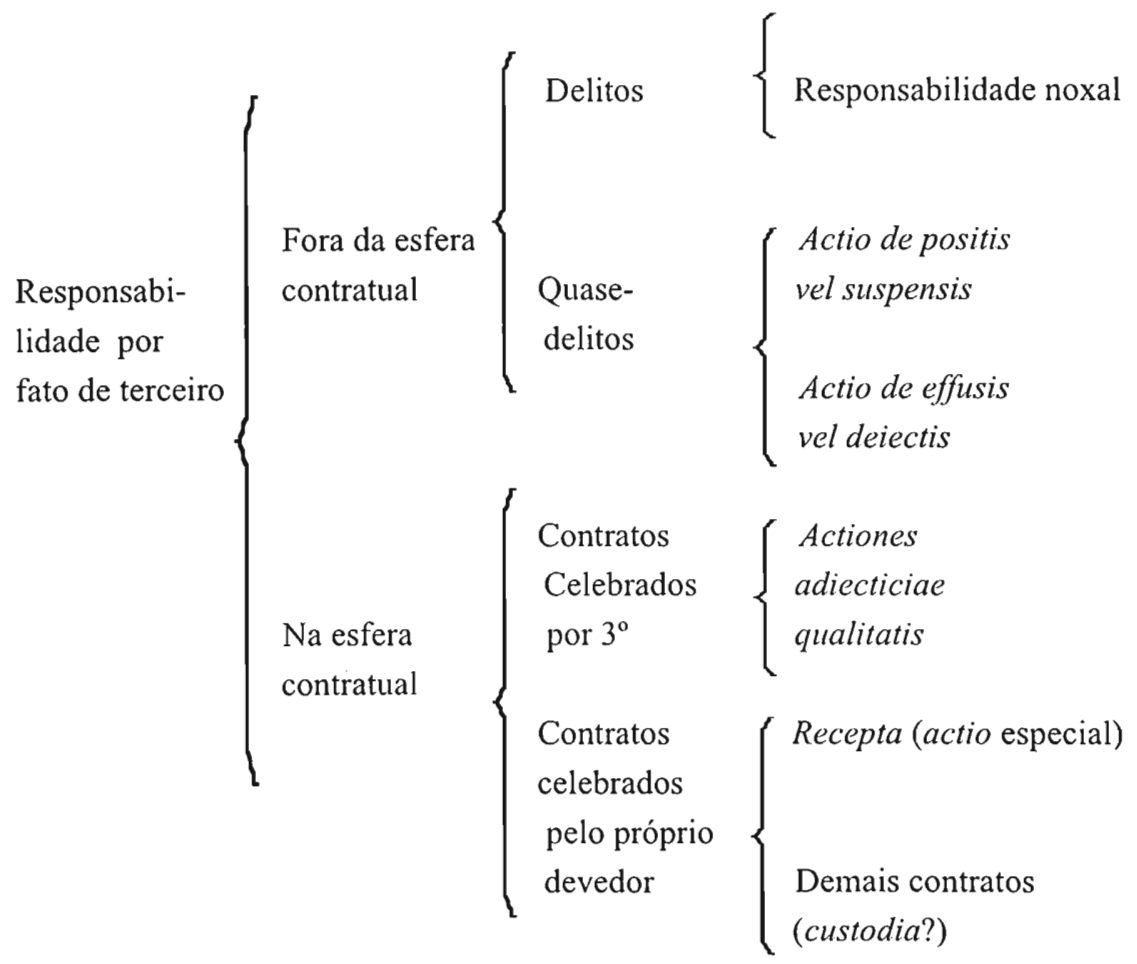

Delimitado, porém esse campo de estudo, antoja-se-nos a seguir outra inelutável questão, que nos leva a considerar o problema sob outro ponto de vista. 
Quando falamos em responsabilidade civil por fato de terceiros, há que se perguntar antes de mais nada que terceiros são esses, e qual a relação jurídica que pode existir entre eles e aquele a quem incumbe responder juridicamente pelos seus atos. Sabemos com certeza que, em dadas circunstâncias, responde o paterfamilias por seus escravos e alieni iuris. Mas as fontes nos dão testemunho de que ele podia responder também por pessoas livres que estivessem de algum modo submetidas à sua esfera de influência. Um desses casos, por exemplo, é o do escravo aparente (homo liber bona fide serviens), pessoa livre que, sendo desconhecida essa sua condição, é reduzido a uma situação servil de fato. É um caso de relativamente pequeno interesse no contexto que estudamos, uma vez que sua situação é em tudo análoga à dos escravos.

Não era impossivel, contudo - e as fontes parecem indicá-lo, como veremos - que uma pessoa pudesse ser responsável também pelos atos de trabalhadores livres contratados ao seu serviço. Embora a mão-de-obra escrava representasse a mais importante força de trabalho na Roma antiga, não escasseavam os trabalhadores livres, os quais se submetiam à autoridade do empregador, por vezes lhe devendo uma obediência que, se não pode ser comparada à de um filius familias ou escravo, tampouco era menos considerável. ${ }^{8}$ De outro lado havia ainda aqueles que atuavam a mando de outrem e no interesse deste, porém de maneira autônoma e com maior liberdade de ação (como o mandatário e o negotiorum gestor), e cumpre investigar em que medida o mandante ou dominus negotii responsabilizavase por seus atos. ${ }^{9}$

Configura-se destarte um segundo modo de organizar a nossa pesquisa, ou seja, não só de acordo com a relação jurídica entre o credor e o devedor, mas também conforme a relação entre este e o terceiro por cujos atos ele se torna civilmente responsável. E, por conseguinte, podemos elaborar um segundo esquema, conforme o que se vê a seguir:

8. A csse propósito ver De Robertis, I Rapporti di Lavoro nel diritto romano, Milano, Giuffrè, 1946, pp. 130 ss.

9. Excluímos os casos de responsabilidades por atos de tutor ou curador, dado que a situação destes ć cspecial, decorrente de institutos de dircito de família, que $\mathrm{cm}$ nada se relacionam com o nosso objeto de cstudo. Ademais, tais pessoas como o tutor $\mathrm{c}$ o curador cram propriamente representantes legais do tutelado ou curatclado, condição que os aproxima dos casos das acõcs adiecticiae qualitatis, que como visto acima cxcluimos do nosso objcto de análise pela mesma razão. Accrca da rcsponsabilidade por atos do tutor, mercec ser consultado, todavia, Knütcl, Dolus tutoris pupillus non nocet, in Iuris Professio Festgabe für Max Kaser zum 80. Geburtstag. Wien/Köln/Graz, Böhlaụ, 1986, pp. 101-126. 
Responsabilidade por fato de $3^{\circ}$

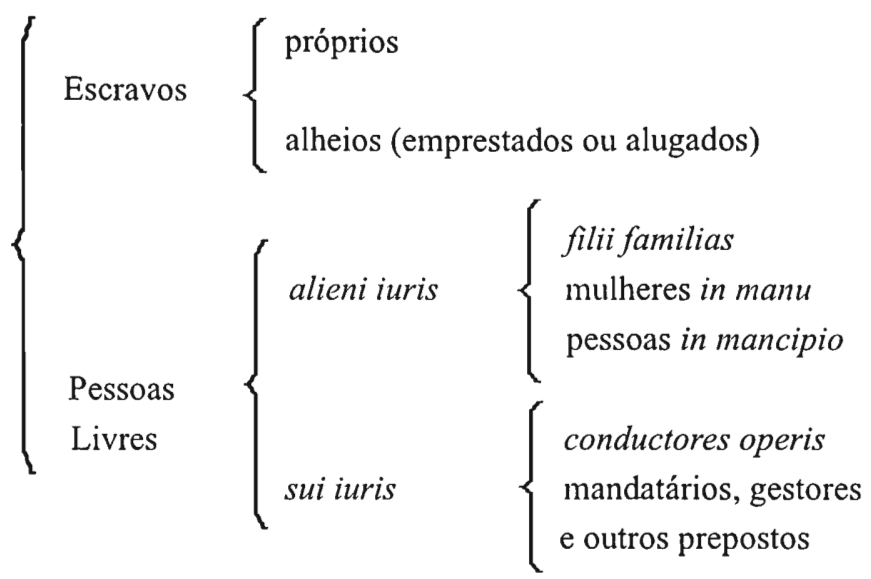

Poderíamos, finalmente - como fez Brinz em sua penetrante e ainda atual exposição da matéria ${ }^{10}$ - distinguir, para todos esses casos, as pessoas que o devedor emprega como meros auxiliares no cumprimento da obrigação daquelas a quem ele indevidamente confiou a execução de uma tarefa que a ele caberia pessoalmente, e também daquelas outras que, embora não tenham participado do cumprimento da prestação, encontravam-se na esfera de influência do devedor, a quem portanto incumbia o dever de vigiá-los."

Examinando de modo conjunto os dois esquemas classificatórios que apresentamos acima, e procurando relacioná-los um com o outro, podemos chegar a uma visão bem abrangente de nossa problemática e já discernir aqueles tópicos que demandam uma atenção especial. De fato, conforme vimos, para cada um dos casos figurados no nosso segundo esquema a casuística romana apresenta diversas soluções singulares, representadas no nosso primeiro esquema. Assim, por exemplo, para os atos praticados por filii familias a iurisprudentia romana concebeu o instituto da noxalidade no caso de responsabilidade delitual e o ius honorum forneceu as actiones adiecticiae qualitatis no de responsabilidade contratual. $\mathrm{O}$ mesmo se poderia dizer com relação aos escravos, e assim por diante.

Desperta-nos a atenção, no entanto, que à última categoria listada em

10. Pandekten, II, § 270.

11. Um interessante c didático esquema gráfico cxplicativo de todas cssas hipóteses nos ć oferccido por FÖLDI (Sulla responsabilità per fatto altrui in diritto romano, in Publicationes Universitatis Rerum Polythecnicarum Miskolciensis - Series Juridica et Politica, Miskolc (Hungria), 1988, tomo III/a, fasciculo 4 , p. 140 . 
nosso segundo esquema (precisamente a dos homens livres e sui iuris, representados no esquema sob a rubrica "conductores operis, mandatários, gestores e outros prepostos") não conseguimos relacionar nenhuma alternativa no primeiro esquema. E de fato, não sendo esses prepostos pessoas submetidas à potestas do paterfamilias, não se aplicaria no caso nem as ações adjetícias, nem as noxais. As únicas hipóteses em que se configuraria uma possível responsabilidade por fato desses terceiros seria nos casos especialíssimos dos recepta ou dos quase-delitos (positum et suspensum, effusum et deiectum), que pelo seu caráter excepcional não podem de modo algum servir de base para uma apreciação sistemática do problema. ${ }^{12}$

Assim sendo, é nosso parecer que o ponto crucial de qualquer estudo sobre a responsabilidade civil por fato de terceiros no direito romano está precisamente na questão de como os fatos desses prepostós livres e sui iuris eram tratados pela iurisprudentia, excluídas as mencionadas hipóteses de recepta ou quasi delicta. Apreciando-a em cotejo com os demais casos já organizados em nossa esquematização poderemos, finalmente, ter uma visão de conjunto do problema e, quiçá, intentar a uma sistematização, se ela for possível.

\section{Princípios Fundamentais}

Precedendo qualquer outra consideração, faz-se mister dar tento ao fato de que, subjacente à questão da responsabilidade por fato de terceiro, no DireitoRomano encontra-se um radical conflito de princípios. O primeiro princípio envolvido é o da responsabilidade estritamente pessoal pelas obrigações no direito romano. De fato, os juristas romanos viam a obligatio como um vínculo estritamente pessoal entre credor e devedor, entre as duas partes envolvidas em uma relação jurídica (no caso das obrigações negociais) ou situação fática (no caso das delituais) das quais esse vínculo se origina. A obrigação "ossibus inhaeret", diz-se, e o reflexo desse princípio no terreno da responsabilidade está na noção de que cada indivíduo é responsável pelos seus próprios atos, devendo sempre assumir as conseqüências jurídicas de suas ações pessoais - e somente elas, não, porém, as de outrem.

12. Discordamos portanto de Serrao, Responsabilità per fatto altrui in diritto romano, in BIDR 66 (1963), pp. 19-34, apcsar de respcitarmos as suas agudas obscrvaçõcs sobrc a importância do ius honorariumm na ampliação da csfera de abrangência desses institutos, os quais certamente têm uma importância não diminuta no panorama geral da responsabilidade por tercciros no dircito romano. Insistimos, porćm, na cxcepcionalidade dos referidos institutos, que representam um compartimento cstanque c isolado, $\mathrm{c}$ não são adcquados para cxplicar a gama maior de situações que a responsabilidade civil (cm particular a contratual) nos antoja. Não deverá scr cssa, portanto, a linha das nossas investigaçōes sobrc o assunto. Nesse particular compartilhamos o scntir de Knütel, SZ 100 (1983), p. 358. 
Como norma geral, essa regra se aplica também hoje entre nós, como fundamento genérico ou primário da responsabilidade, embora não como um pétreo mandamento absoluto e universal. Entre os romanos, porém, dada a forma como compreendiam as relações obrigacionais, era considerada com um rigor muito maior, posto que visceralmente ligada à própria natureza jurídica do liame obrigacional. Sinal disso é a idéia romana de que todos os bens que viessem a ser adquiridos, por exemplo, por escravos ou alieni iuris passavam a integrar o patrimônio do paterfamilias (haja vista a que aqueles careciam por completo de capacidade patrimonial) mas não assim - ou ao menos não necessariamente ou de modo irrestrito - os débitos por eles contraídos. Do mesmo princípio decorre também a relutância do jurista romano (ao menos no direito clássico) em admitir uma verdadeira transmissão das obrigações ou a representação direta nos negócios jurídicos. O princípio da responsabilidade estritamente pessoal é tão geral que findou por cristalizar-se em uma regula iuris : "non debet nocere factum alterius" 13

Mas, como se verifica tão freqüentemente no pensar jurídico romano, esse princípio contrasta e se choca com outros não menos relevantes e reiteradamente afirmados pelos jurisconsultos. Como sói acontecer em tais casos, o resultado desse choque é uma fusão e um abrandamento recíproco de ambas as tendências. À questão da responsabilidade por fato de terceiro subjaz o conflito entre duas normas ou princípios opostos: por um lado, o já citado: "non debet nocere factum alterius"; de outro, a noção de que quem recebe as vantagens ou benefícios de uma situação deve correspondentemente sofrer também as perdas que essa mesma situação originar. E do mesmo modo que o primeiro, também esse outro princípio foi consubstanciado em uma máxima ou brocardo: "cuius est commodum, eius debet esse onus" ${ }^{14}$ Assim,

13. A rcgra ć citada por Ulpiano $\mathrm{cm}$ D. $39.1 .55 \mathrm{~cm}$ uma formulação muito próxima à que mencionamos: "neque enim debet nocere factum alterius ei qui nihil fecit". Aparcce, porćm, sob formas diversas mas com o mesmo contcúdo csscncial, $\mathrm{cm}$ muitas outras passagens das fontes, $\mathrm{c} \mathrm{cm}$ variados contextos; a cxemplo de: D. 8.8.61 Celsus $V$ dig. "Nec me fallit alieno facto ius alterius immutatum iri (...)": D. 44.4.11.pr Ncratius IV membran. "Neque alienus dolus nocere alteri debet". Para uma apreciação desses fragmentos na perspectiva da regula que ora cstudamos, ver Knütcl, SZ 100 (1983), pp. 359 ss..

14. A regula iuris aparece cm D. 50.17.10 Paul. III ad Sab. "Secundtum naturam est commoda cuitusque rei eum sequi, quem sequentur incommoda". Em diversos outros fragmentos cxpressa-sc idćia scmellhantc: D. 17.2.55 Ulp. XXX ad Sab. "Aequum est enim, ut cuitus participavit lucrum participet et dammum". Atć mesmo o munus (do tutor legítimo) de exercer a tutcla cra cxplicado por Justiniano com basc nesse principio: Inst. I, 17 "Ubi successionis et emolumentum, ibi et tutelae onus esse debet" Raciocinando contraria ratione, a aquisição de propricdade por acessão após a compra do objeto principal c antes do ato translativo de propricdade cra atribuida ao comprador, como contrapartida por the tocarcm os riscos da coisa: Inst. 3,23,3 "nam et commodum eius esse debet, cuitus periculum est". A regra foi recebida pelo dircito canônico: "Qui sentit onus, sentire debet commodum, et contra" (Bonifácio VIII, Liber VI, 5,13,55); 
prosseguindo com o exemplo dado no parágrafo anterior, não pareceu bem ao senso ético romano que o paterfamilias, lucrando pela atividade de seus subordinados, não respondesse pelos débitos por eles contraídos. Desse princípio se originaram os já citados institutos da noxalidade e das actiones adiecticiae qualitatis.

No campo que nos interessa - a responsabilidade contratual por fato de terceiro - o antagonismo entre os dois princípios é meridianamente patente. A questão agora é considerar em que medida e de que forma terá ocorrido, na casuística trazida pelas fontes, uma integração entre os dois princípios. Nesse particular, o primeiro texto que certamente chama a atenção do estudioso da matéria é uma taxativa negação de Juliano:

\section{13,6,19 Iulianus I dig.}

Ad eos, qui servandum aliquid conducunt aut utendum accipiunt, damnum iniuria ab alio datum non pertinere procul dubio est: qua enim diligentia consequi possumus, ne aliquis damnum nobis iniuria det?

\section{TRADUÇÃO NOSSA:}

Está fora de dúvida que àqueles que (em razão de uma locação de serviços) tomam algo sob sua guarda, ou o recebem para usar, não toca o dano ilicitamente causado por outrem: pois com que diligência podemos conseguir que alguém não nos cause dano ilicitamente?

Trata-se, à primeira vista, de um radical repúdio à responsabilidade por fato de terceiros, ao menos no que respeita à locatio conductio e ao comodato. $\mathrm{O}$ sentido pretendido por Juliano mostra-se claro: é certamente dever do conductor ou comodatário usar de toda diligência para evitar acidentes que possam causar danos à coisa a ele confiada. Mas a Juliano parece evidente que nem com toda a diligência se pode evitar que outros - por descuido ou mesmo dolosamente - provoquem esse dano. É certamente, à primeira vista, um pensamento um tanto simplista do grande Juliano, que destarte poria ponto de modo peremptório à discussão sobre o tema que ora investigamos.

É porém, necessário, estudar o texto de Juliano em conforto com a seguinte passagem paralela de Ulpiano:

\footnotetext{
"Ad quem spectat onts, et emolumentum" (Damasus, Regulac Canonicac, 75). No Dircito moderno, comparar, por excmplo, com o $\$ 905$ do BGB alcmão. Trata-sc de uma idćia tão clcmentar de equilibrio c justiça, que se reflete atć mesmo nos antigos adágios da sabedoria popular, tais como "quem collac as rosas deve colher tambćm os cspinhos", ou "quem come a carne deve também rocr os ossos"
} 


\section{D.19,2,41 Ulpianus Vad ed.}

Sed de damno ab alio dato agi cum eo non posse Iulianus ait: qua enim custodia consequi potuit, ne dammum iniuria ab alio dari possit? Sed Marcellus interdum esse posse ait, sive custodiri potuit, ne damnum daretur, sive ipse custos damnum dedit: quae sententia Marcelli probanda est.

\section{TRADUÇÃO NOSSA:}

Mas diz Juliano que contra ele não se pode propor ação acerca de um dano causado ilicitamente por um outro: pois com que cuidado poderia conseguir-se que um dano não possa ser causado ilicitamente por outrem? Marcelo, entretanto, diz que se pode (propor a ação), ou se fora possível zelar para que o dano não fosse causado, ou se o próprio guardador da coisa causou o dano; tal opinião de Marcelo deve ser aprovada.

Aparentemente, Juliano se mostra mais inflexível, recusando-se categoricamente a atribuir responsabilidade ao locador de serviços ou comodatário, ao passo que Marcelo adota uma visão menos estreita, divisando hipóteses em contrário, raciocinando de maneira mais aberta. $O$ fragmento mantém coerência com as opiniões de Juliano, que em D. 9,2,11,9 nega ao comodatário a legitimação ativa para a acitio legis Aquilia; a correlação entre essa legitimação e a responsabilidade por custodia aparece distintamente em Gai 3,205 e é aceita pela unanimidade dos estudiosos da matéria. O problema é enterder o motivo dessa divergência, Por Juliano exclui o damnum iniuria datum causado por terceiros - e apenas a esse caso se refere a discussão - da esfera de abrangência da responsabilidade e Marcelo não?

Parece-nos que Metro ${ }^{15}$ elucida com penetrante visão o pensamento de Juliano: ao contrário do damnum, o furtum na concepção clássica era um delito que não implicava violência alguma do agente, e por isso poderia - em tese - ser sempre evitado por meio da devida vigilância, ou seja, a devida custódia (em sentido não técnico), que era o dever primordial de quem respondia pela custodia (em sentido técnico); já o dano, trazido por um ato de violência de terceiro, não poderia ser evitado apenas pelo vigilante zelo, por mais diligente que este fosse, e por isso não estaria incluído na custodia. Albanese chega a dizer que esse argumento de Juliano é absurdo, que não faz sentido na lógica do direito clássico. ${ }^{16}$ Em verdade nada tem de absurdo o argumento de Juliano,

15. L'obbligazione di custodire, Milano, 1966, p. 120.

16. Albancse, Studi sulla lex Aquilia, in Annali Palcrmo v. 21, 1950, p. 293; c do mesmo autor, “D.13.6.19 e D.19.2.4I nel quadro dei problemi della 'custodia' ", in St. in Onore di Giuseppe Grosso, 
que é adotado igualmente por Nerácio em D. 19.1.31.3 com relação à rapina (delito praticado com violência): “...quia custodia adversus vim parum profecit”"

Em contrapartida Marcelo, discordando de Juliano, opina que é possível responsabilizar judicialmente o prestador de serviços ou comodatário (certamente o "posse" de Marcelo corresponde ao "cum eo agi non posse" de Juliano), e aduz para corroborar sua idéia duas hipóteses em que se verifica essa possibilidade: se tivesse sido possível vigiar para que o dano não ocorresse, ou se o causador do dano fosse o próprio guardião da coisa danificada.

O que diferenciaria então, para Marcelo, esses dois suportes fáticos um do outro, ou seja, aquele no qual o obrigado responde pelo dano daquele em que não responde? Quando ele afirma que o obrigado é responsável se podia vigiar para que o dano não ocorresse, subentende-se naturalmente que, se o dano ocorreu, é porque o mesmo foi omisso no seu dever de bem custodiar a coisa. Inegavelmente, essa argumentação traz à idéia a noção de culpa do devedor, isto é, de uma conduta negligente e portanto subjetivamente culposa de sua parte. A aceitar essa interpretação, chegaremos à conclusão de que, para Marcelo, o prestador de serviços e o comodatário respondem por culpa própria no caso de dano trazido por terceiros.

Muitos autores tendem a aceitar essa admissão de um elemento subjetivo na responsabilidade por dano. ${ }^{17}$ Assim entendida a questão, a diferença entre Marcelo e Juliano estaria no fato de que este último pensaria apenas no caso mais geral em que

1968, p.84.. Essa tem sido a opinião de muitos autores no passado: Haymann, SZ 40 (1919), p. 195 afirma - na verdade cxclama admirado - que uma tal pergunta retórica não poderia provir do clássico Juliano, $\mathrm{c}$ na p. 197 referc-se a cla como "unerträgliche rhetorische Frage". E já Baron, in Arch. fïr die zivil. Praxis 78 (1892), considerava o argumento tão crrônco, que se não vicsse do grande Juliano nem scria digno de atenção : "Wir tun das nur Julians halber" (p. 250).

17. Por cxcmplo Mac Cormack in SZ 89 (1972), p. 172; PASTORE, Commodato, Contratto, Responsabiliti, Milano, 1986, p.364, para quem o sive custodiri potest implica "nccessariamente" uma responsabilidade subjetiva. Arangio-Ruiz (Responsabiliti Contrattuale in Diritto Romano, Napoli, Jovenc, 2 cd. 1958, p. 168) admitc que o caráter estritamentc objctivo da responsabilidade por custódia foi rompido com cssas ponderaçōes accrca da cvitabilidade do dano; De Robertis, La responsabilità contrattuale nel sistenta della grande compilazione, Bari, Cacucci, 1983, v. 2, p. 667 nt. 103 crê que a primcira hipótese de Marcclo scja caso de concorrência de culpa do obrigado, mas ć bem verdade que cstc autor sc ocupa apenas com o dircito justiniancu, c por isso, provavelmente, adotou essa linha excgética sem se prcocupar com a hipótesc de uma dluplex interpretatio. Não deve haver dúvida de que no sistcma do Corpus Iuris os pós-clássicos entendessem o texto de tal forma, semprc apegados ao princípio da culpa. De resto, a pandectística c os autores do sćculo passado, que accitavam o dircito da compilação tal como fora recebido, scm sc prcocupar com uma critica históricodogmática, não hesitavam $\mathrm{cm}$ apontar a culpa do comodatário que custodire potuit como a clave da objeção de Marcclo a Juliano (cf. c.g. Windschcid, Pandekten II, § 401, p. 747, nt. 5; Hassc, Die Culpa des römischen Rechts, Bonn, A. Marcus, 1838 [rcimpr. Aalen, Scientia Verlag, 1963], pp. 407-409). 
o obrigado não tivesse culpa, enquanto o primeiro, com maior precisão e rigor, lembrou que em alguns casos poderia haver culpa concorrente do próprio obrigado.

Essa interpretação, no entanto, apresenta dificuldades. A idéia hoje mais aceita pela doutrina romanística é que, no direito clássico, a custodia era compreendida como uma responsabilidade objetiva do devedor, no sentido de que a sua responsabilidade decorria apenas da circunstância objetiva da ocorrência de dano que não fosse causado por vis maior, sem levar em consideração a conduta culposa ou não do devedor, a quem não se facultava a possibilidade de exculpação ainda que provada a ausência de culpa sua. ${ }^{18}$ Diante disso, não se entende que Juliano e Marcelo adotariam um critério subjetivo de responsabilidade, baseado na culpa do obrigado. Mais ainda: se a culpa não era considerada nos demais casos, como os de furto, por que iria Marcelo abrir exceção especialmente para os casos de dano?

Parece-nos que a melhor interpretação, que concilia de maneira plausível os dois fragmentos, é a proposta por Rastätter," e já antes vislumbrada por ArangioRuiz. ${ }^{20}$ Juliano provavelmente negava a responsabilidade do comodatário ou prestador de serviços baseado na já referida idéia de que a simples vigilância não é capaz de impedir o dammum iniuria datum, delito praticado por meio de vis. Esse raciocínio, como salienta Rastätter, é puramente formalista: certamente Juliano sabia que, se a questão for considerada casuisticamente, não será de todo impossível, em certos casos, evitar o dano; ocorre apenas que ele aqui não trabalha com a casuística, mas, fugindo dela (e quiçá fiel à idéia da objetividade da responsabilidade por custodia), faz essa abstração apenas formal.

Já Marcelo estende e amplia o pensamento de Juliano, mas sem contrariar o princípio da responsabilidade objetiva: ele considera que em muitos casos é possível com a devida vigilância evitar o dano. Com isso ele não está refutando as regras da custodia, nem transferindo a discussão do problema para o terreno da culpabilidade do obrigado. O seu raciocínio é igualmente formalista, e considera o problema sempre objetivamente: não é a conduta menos ou mais diligente do obrigado que irá determinar se o dano poderia ser evitado. $O$ fator determinante são as características não só do

18. Gaio, por cxemplo, asscvera cm D. 19.2.41 com relação ao locador de scrviços: "Quii mercectèm accipit pro custodia alicuius rei, is huius periculum custodiac praestat". O fato de o fragmento de Ulpiano scguir imediatamente a cste no Digesto confirma que os compiladores cntendiam a réplica de Marcelo como uma limitação da responsabilidade do concluctor aos casos $\mathrm{cm}$ que cle tivesse culpa própria.

19. Marcelli notae ad Juliani digesta (tese de doutorado, Freiburg, 1980), p.202.

20. Responsabilità Contrattuale... (cit. nt $\backslash \mathrm{h} 17$ supra), p. 168. 
objeto quanto à sua adequação para ser protegido por meio de vigilância (como propõe Rastätter), mas também das próprias circunstâncias em que se deu o dano, se vi ou clam. O que Marcelo teria feito, portanto, foi apenas emendar Juliano, lembrando que em circunstâncias especiais e objetivamente determináveis (poderíamos conjeturar por exemplo a hipótese de que o autor do dano se tivesse aproximado clam clandestinamente) o dano poderia ser evitado por uma estreita vigilância sobre a coisa. Resta ainda examinar a segunda hipótese de Marcelo (sive ipse custos damnum dedit). Mayer-Maly² não aceita o texto como genuíno, alegando que o ipse custos de Marcelo está em contradição com o alius de Juliano, pois se é o próprio custos o causador do dano, então não se trata de dano ab alio dato. Albanese ${ }^{22}$ reafirma essa opinião, achando que essa hipótese fugiria ao tema em discussão. É surpreendente que os dois eminentes autores não tenham enxergado o óbvio nesse fragmento: que o ipse custos a que se refere Marcelo não era a própria pessoa do comodatário (ou prestador de serviços), mas um terceiro por ele encarregado de vigiar a coisa em seu lugar.

Com lucidez e clareza enxergaram o problema Cannata, ${ }^{23}$ Rastätter $^{2+} \mathrm{e}$ Knütel. ${ }^{25}$ É evidente que Marcelo não poderia ter perdido de vista o fato de que o ponto discutido era o dano causado por terceiro, não cometeria tamanha desatenção. Não pode restar dúvidas de que o ipse custos é um alius, uma pessoa encarregada pelo obrigado de zelar pela coisa guardada. $\mathrm{O}$ argumento de Albanese de que o pronome ipse indica - segundo ele "com clareza inequívoca" - que o causador do dano é o próprio comodatário ou conductor é de todo falto de fundamento. $\mathrm{O}$ ipse significa apenas que o causador do dano foi o próprio custos, o próprio guardião da coisa; que esse custos e o obrigado sejam a mesma pessoa é uma idéia que de forma alguma se pode inferir do texto.

Muito pertinente a conjetura de Cannata de que esse terceiro fosse uma pessoa livre contratada pelo devedor - já que um seu escravo dificilmente seria pensado por Marcelo como um alius. É, por outro lado, absolutamente irrelevante a objeção de Albanese (que considera "original" essa simplesmente natural conclusão) o qual, repetindo outro truismo, lembra que para os romanos o preposto não era considerado

21. Locatio Conductio, München, Herold, 1956, p. 205.

22. Studi sulla lex Aquilia, in Annali Palermo v. 21 (1950) p. 294.

23. Ricerche sulla responsabilità contrattuale nel diritto romano, Milano, Giuffrè, 1966, p. 73.

24. Marcelli notac... (cit. nt. Ih 19 stipra), p. 204.

25. SZ (1983) 100, p. 411. 
um "órgão" do preponente, e portanto não deveria haver diferença entre o dano causado por ele ou por outros alii, nem teria sentido a nota de Marcelo. Em lugar nenhum Marcelo indica que a responsabilidade decorre da idéia de que o preposto fosse um representante ou "órgão" do preposto, e não é possível imaginar de onde Albanese tirou essa idéia.

Concluímos portanto que, ao contrário do que poderia à primeira vista parecer, o comentário de Juliano em D. 13,6,19 não representa uma adesão incondicional à regra "non debet nocere factum alterius" Em verdade, a correta interpretação desse fragmento em conexão com o comentário de Marcelo transmitido por Ulpiano em D.19,2,41 nos confirma de maneira irretorquível que a regra não era aplicada de modo absoluto, nem representa ela por si só um empecilho ao desenvolvimento de uma doutrina da responsabilidade civil por fato de terceiro.

Há, ainda, um último aspecto relevante com relação a esses fragmentos, ao qual nos parece que não tem sido dada a devida relevância pela doutrina moderna. Concluímos que, no tocante à primeira hipótese de responsabilidade do obrigado apresentada por Marcelo ("sive custodiri potuit"), o critério de imputação era a inevitabilidade ou não (em princípio, provavelmente considerada in abstracto) do dano causado. Muito mais interessante, porém, para o nosso estudo, é a segunda hipótese ("sive ipse custos damnum dedit"). Trata-se aí não somente de uma inequívoca referência expressa a uma responsabilidade por fato de terceiro, como também resulta da literalidade da argumentação de Marcelo que o simples fato de o custos (um terceiro a quem o devedor delegou suas tarefas) ter causado o dano é suficiente para acarretar a responsabilidade do obrigado.

É muito notável que para esse último caso Marcelo não tenha feito nenhuma ressalva, não tendo considerado, por exemplo, se esse terceiro custodiri potuit, de sorte que o dano fosse evitado, ou não; isto é: não considerou se esse custos teve a "cura aut diligentia" adequada ou não, se ele causou o dano por culpa sua ou se foi um acidente normal, que mesmo um custos cuidadoso poderia ter causado. O obrigado, ao que parece, responde sempre, bastando a comprovação de que o dano foi causado pelo custos.

Essa responsabilidade acentuada no caso de o terceiro, causador do dano, ser um preposto do comodatário ou prestador de serviços (em comparação com a primeira hipótese de Marcelo, em que o terceiro era claramente pessoa alheia à esfera do obrigado), é um detalhe da máxima importância, e requer uma explicação. Por que a responsabilidade era incondicional nesse caso? Poderia ser pelo fato de o obrigado ter delegado a terceiro uma tarefa que, em princípio, a ele pessoalmente caberia cumprir. 
É porém talvez exagerada essa conclusão, já que não necessariamente se pode entender a guarda da coisa como uma obrigação intuitu personae, e é sabido que a utilização de auxiliares para semelhantes tarefas era coisa comum para os romanos (como o é hoje), e o senso comum jurídico (sempre um poderoso instrumento para entender o pensamento dos jurisconsultos romanos) parece não apoiar essa idéia.

Mais provável nos parece que esteja subjacente à decisão de Marcelo, de forma consciente ou não, a idéia de que quem se utiliza de um terceiro para realizar uma tarefa em seu beneficio, deve em contrapartida assumir os riscos do prejuízo que esse terceiro possa trazer como consequiência de sua atividade. Ou seja: cuius est commodum, eius debet esse onus. Voltamos aqui, portanto, à discussão

inicial deste capítulo, e às duas máximas ou regulae que ilustram os dois princípios fundantes da matéria cujo estudo ora tomamos a peito. Vimos aqui de que modo admirável esses dois princípios se podem completar um ao outro e entrelaçar-se para dar origem às soluções práticas que encontramos nas fontes romanas. Verificamos, assim, que a responsabilidade civil por fato de terceiro, conquanto jamais erigida em doutrina pelos juristas romanos, longe está de ser incompatível com os princípios basilares do direito romano, mas, ao contrário, deles deriva de forma quase inevitável.

\section{A Casuística das Fontes}

Passaremos agora a analisar brevemente a casuística encontrada nas fontes romanas e, tendo em vista as conclusões até aqui atingidas, buscaremos as respostas aos problemas que identificamos no capítulo inicial. o primeiro fragmento que nos importa analisar é o famoso caso da columna transportanda, que nos é relatado por Gaio na seguinte passagem:

D. 19,2,25,7 Gaius X ad ed. prov.

Qui columnam transportandam conduxit, si ea, dum tollitur aut portatur aut reponitur, fracta sit, ita id periculum praestat, si qua ipsius eorumque, quorum opera uteretur, culpa acciderit: culpa autem abest, si omnia facta sunt, quae diligentissimus quisque observaturus fuisset. Idem scilicet

\section{TRADUÇÃO NOSSA:}

Quem recebeu uma coluna para ser transportada, se esta se quebrar enquanto estiver sendo removida, carregada ou recolocada, responde por esse risco se tal tiver ocorrido por alguma culpa sua e daqueles cujo trabalho ele tiver empregado: culpa porém não há se tiver sido feito tudo o que alguém diligen- 
intellegemus et si dolia vel tignum transportandum aliquis conduxerit: idemque etiam ad ceteras res transferri potest tíssimo teria observado. O mesmo, certamente, também entenderemos se alguém receber tonéis ou caibros para transportar: e o mesmo se pode aplicar às demais coisas.

Tudo parece indicar que os trabalhadores empregados pelo conductor, ou ao menos parte deles, sejam com muita probabilidade pessoas livres e contratadas, e não somente escravos seus. ${ }^{26}$ Isso afastaria a possibilidade de uma noxalis deditio $\mathrm{e}$ traria à tona precisamente a discussão estrita da responsabilidade por fato de terceiro como é nosso desejo enfocar. Observemos, ademais, que, não obstante a expressão "periculum praestat". o que ao menos à primeira vista a literalidade do fragmento parece indicar é que esteja ocorrendo não uma assunção dos riscos da coisa, mas sim da responsabilidade por ela, já que Gaio subordina o dever de indenizar a uma conduta culposa do conductor ou de seus auxiliares. ${ }^{27}$ Sendo assim, estaremos diante de um texto que formalmente admite a responsabilidade civil do conductor operis pelo fato de terceiros livres e independentes.

A maior parte da doutrina mais recente já aceita como fato seguro que Gaio utilizou a enclítica com sentido disjuntivo, não exigindo que ambos - o conductor e seus empregados tivessem conjuntamente incorrido em culpa. ${ }^{28} \mathrm{O}$ conductor respondia, portanto, até mesmo em caso de culpa exclusiva de seus trabalhadores. Precisamos agora indagar qual será o fundamento dessa responsabilidade. Quer-nos parecer que o trecho que serve de fulcro à idéia essencial contida no fragmento é o "culpa autem abest". Já foi há tempos observado na época de Gaio a doutrina da culpa

26. Compartilham essa opinião: De Robertis, La responsabiliti contrattuale nel sistema della grande compilazione, v. 1, Bari, Cacucci, 1983, p. 433 nt. 83; Mac Cormack, Culpa in eligendo, in RIDA 18 (1971), p. 54I; Molnár, Gefahrtragung beim römischen Dienst- und Werkvertrag, in Labeo 21 (1975), p. 42

27. Obscrva Molnár (Rida 18, p. 24) que cm casos limitrofes como csse nem scmpre ć fácil distinguir o risco ("Gefalwtragung") da responsabilidade ("Verantwvorfung"), mas ao final acaba concordando com o nosso ponto de vista: "Von einer Gefahrtraglung kann die Rede sein, wenn Schäden entstanden, die niemandem zugerechnet werden kömnen" (p. 25).

28. Expressamentc: Krückmann, Periculum emptoris in SZ 60 (1940), p. 18; Pflüger, Zur Lehe ron der Haftung des Schuldners nach römischen Recht in SZ 65 (1947), pp. 195-196, cmbora considere a parte restante do fragmento interpolada; Knütcl, SZ 100 (1983) pp. 419 ss. c nt. 352, tb. p. 372 nt. I3I; Zimmerman, The Law of Obligations - Roman Founclations of the Civilian Tradition, Capc Town/Wetton/ Johanncsburg, Jutta., 1990, pp. 399-400. 
já estava suficientemente consolidada, e não seria necessário, nem razoável, que ele repetisse o conceito de culpa na discussão de um caso específico, a não ser que pretendesse atribuir-lhe uma nota distintiva, que se afastasse do conceito normalmente aplicável. Provavelmente, o que Gaio fez foi ampliar esse conceito de culpa, o que se evidencia pelo "diligentissimus" Também as palavras "idemque...potest" deixam claro que Gaio está tratando de um caso excepcional, que foge à regra e não se aplica a todas as coisas, nem a todas as situações. Nada disso seria preciso se o conductor respondesse apenas por culpa leve própria in eligendo.

O termo diligentissimus parece denotar um grau de exigência extremo no tocante à conduta do conductor: não basta que ele seja diligente, há que ser o mais diligente possivel. Não se pode imaginar outro motivo para que o jurisconsulto fizesse questão de usar o adjetivo no superlativo, em lugar do habitual diligens. Diligentissimus é raríssimo nas fontes: além do fragmento ora em exame, esse termo só ocorre outras três vezes em todo o Digesto, todas em situações especialíssimas. ${ }^{29}$ A terceira ocorrência merece maior atenção, por ser também do próprio Gaio e referir-se a uma situação de responsabilidade contratual, e tirada precisamente dos mesmos livros de comentários ao edito provincial:

D.13,6,18 pr. Gai. 9 ad ed. provinc. In rebus commodatis talis diligentia praestanda est, qualem quisque diligentissimus pater familias suis rebus adhibet, ita ut tantum eos casus non praestet, quibus resisti non possit, veluti mortes servorum quae sine dolo et culpa eius accidunt, latronum hostiumve incursus, piratarum insidias, naufragium, incendium, fugas servorum qui custodiri non solent.

\section{TRADUÇÃO NOSSA:}

Com relação à coisas dadas em comodato, deve ser cumprida uma diligência como a que todo diligentíssimo paterfamilias empregà, de tal sorte que só não responda por aqueles casos aos quais não se pode resistir, como a morte de escravos que ocorra sem culpa sua, ataque de ladrões ou inimigos, emboscadas de piratas, naufrágio, incêndio, fuga de escravos que não se costumam vigiar.

29. A primcira, Ulp. (11 ad cd) D.4.4.11.5, num caso onde se ncga a restitutio in integrum a um menor afirmando-se que atć mesmo um diligentissimus paterfamilias estaria sujcito a ter sofrido o mesmo prejuizo que o menor sofrcu, $\mathrm{c}$ portanto cle não podcria atribuir isso à sua cxpcriência pcla pouca idadc; nessc caso ć cvidente que o supcrlativo foi cmpregado com a finalidade de cnfatizar que até mesmo um paterfamilias com uma diligência acima do comum podcria incorrer $\mathrm{cm}$ tal situação. A scgunda ocorrência de diligentissimus ć cm Ulp. (41 ad cd.) D.37.10.3.5, agora na forma adverbial diligentissime, c completamente fora do contexto que nos intercssa: Ulpiano afirma que o pretor deve investigar "com a máxima diligência" uma questão refercnte tambćm a um impúbcrc. 
Realmente, vemos que nesse caso Gaio usa o grau superlativo porque pretende atribuir ao comodatário uma responsabilidade agravada, exigindo dele uma diligência maior do que o habitual, ficando excluídos dessa responsabilidade tãosomente os casos previstos de vis maior. Não se pode, absolutamente, pretender que o diligentissimus quisque seja terminus technicus para responsabilidade objetiva. O que parece certo, porém, é que esse termo fosse usado sempre que o jurisconsulto pretendia descrever uma situação de responsabilidade aumentada, de exigência maior da diligência do devedor, de restrição nas possibilidades de exculpação.

O próprio Gaio tratou de especificar em cada caso os limites dessa responsabilidade: para o comodatário, eram aqueles "casus quibus resisti non possit" apenas exemplificados em seguida nos casos de naufrágio, violência de terceiros ou acidentes naturais. Já para a "columna transportanda" ele apenas exigiu que fossem observadas todas as precauções que o diligentissimus quisque tomaria, mas não limitou esses casos de exculpação à vis maior, deixando com certeza ao bom senso do iudex privatus avaliar, no caso concreto, se essa diligência máxima esteve presente ou não. É quase como se o diligentissimus quisque fosse nesse caso a figura imaginária do paterfamilias ideal, incapaz de cometer o mínimo deslize, a mínima falta. Ou seja: um padrão ideal para medir uma espécie de culpa levissima in abstracto. Em teoria, a responsabilidade do conductor da coluna também foi, realmente, aumentada quase até o limite da força maior. A diferença prática entre os dois casos é porém patente: no primeiro, o comodatário só se isenta de responsabilidade se conseguir provar a ocorrência de um casus maior, de uma vis cui resisti non possit; já no segundo, basta ao conductor demonstrar que foi impecavelmente diligente e tomou as precauções omnia quae diligentissimus quisque observaturus fuisset.

Nessa linha de raciocínio, não podemos senão concordar com Knütel ${ }^{30}$ em que a formulação "culpa autem abest.. " só pode significar que existe a possibilidade de eximir-se o conductor de responsabilidade, cabendo a ele o ônus de provar que não houve culpa entendida no grau em que Gaio a descreveu sua própria e nem de seus trabalhadores. Trata-se, portanto, de responsabilidade por culpa ainda que agravada até quase só excluir a força maior e presumida iuris tantum e não há falar em assunção de risco ou dever incondicional de garantia, mas de uma verdadeira responsabilidade por fato (culpa) de terceiro. 
Outro fragmento que merece estudo é o seguinte, atribuído a Alfeno Varo:

D. 19,2,30,2 Alfenus lib. VII dig. Qui mulas ad certum pondus oneris locaret, cum maiore onere conductor eas rupisset, consulebat de actione. Respondit vel lege Aquilia vel ex locato recte eum agere, sed lege Aquilia tantum cum eo agi posse, qui tum mulas agitasset, ex locato etiam si alius eas rupisset cum conductore recte agi.

\section{TRADUÇÃO NOSSA:}

Alguém que tinha alugado mulas para que fossem carregadas até um certo peso, tendo-as o locatário estropiado com uma carga maior, consultava acerca da ação a propor. Respondeu que corretamente age ele pela ação de locação, mas pela lex Aquilia só se pode processar aquele que tivesse conduzido as mulas; pela ação de locação corretamente se pode propor ação contra o locatário também se um outro as houvesse estropiado.

O ponto central que primeiramente nos interessa é que, pelo que se depreende do texto de Alfeno, não foi o locatário quem pessoalmente conduzia as mulas sobrecarregadas, mas sim um terceiro presumivelmente sob suas ordens (o "alius" a que se refere o jurisconsulto). Tudo parece indicar que esse "alius" não era escravo e nem pessoa alieni iuris submetida à potestas do conductor - ou, no mínimo, Alfeno considerou a possibilidade hipotética de que não o fosse. A não ser assim, não faria sentido algum falar em uma actio legis Aquiliae contra ele, sendo ao contrário cabível uma actio noxalis contra o conductor. Concordando com essa premissa, Mac Cormack $^{31}$ concebe duas explicações possiveis para o fragmento: ou o almocreve era um trabalhador livre a serviço do conductor, ou um sublocatário deste a menos que por qualquer motivo os animais tivessem sido apropriados indevidamente por um terceiro, o que já é uma hipótese menos provável.

Vemos então que ele responde ex locato. E responde certamente não pelo evento do dano em si ou seja, não como simples "Gefahrtragung" ou "Versicherungshaftung" - mas pelo fato de que as azêmolas foram submetidas a uma carga superior à avençada. Em suma: responde pelo descumprimento de uma cláusula contratual, ${ }^{32}$ muito embora essa cláusula tenha sido violada por um terceiro livre e independente de sua potestas.

31. "Culpa in eligendo", in RIDA 18 (1971), p. 534. Tambćm no mesmo sentido SARGENTI, "Problemi della responsabilità contrattuale", in SDHI 20, 1954, p. 159.

32. Cannata (Ricerche... [cit. nt. lh 23 supra], p.78) acredita quc Alfeno não considera a sobrecarga das alimárias uma violação do dever de custodia - que poderia ensejar a discussão de uma responsabilidade objetiva, decorrente do simples dano - mas apenas uma inobservância dos limites contratuais. Considerando cvidente 
Não fica claro da leitura do fragmento qual é a base da responsabilidade nem qual poderia ser a eventual exculpação do conductor. Alfeno diz apenas que é possível agir em juízo contra o locatário ainda que outro tivesse estropiado as alimárias. Não diz em que condições isso é possível, nem por qual motivo, e nem se existe alguma defesa possivel para ele. Nenhum indício de culpa in eligendo pode ser aí rastreado. Nossa opinião é que, se Alfeno e Sérvio estavam a dar como tudo indica uma resposta completa sobre o caso, não é razoável supor que a apresentassem de maneira tão falha. Se foi afirmado que se pode processar o locatário ex locato porque o limite do contrato foi desrespeitado, e mais nada, podemos entender que era exatamente isso que os jurisconsultos pretenderam dizer: o conductor responde pela culpa de seus ajudantes como se sua fosse, sendo sua responsabilidade exclusiva velar pela observância da norma contratual. Com essa interpretação, chegamos a uma conclusão semelhante à do efeito disjuntivo do -que no caso da "columna transportanda"

Há, no entanto, um outro texto importante que se refere à atuação de uma pessoa sui iuris como uma espécie de "Erfüllungsgehilfe":

D. 19,2,13,1 Ulpianus. YXII ad ed.

Si navicularius onus Minturnas vehendum conduxerit et, cum flumen Minturnense navis ea subire non posset, in aliam navem merces transtulerit eaque navis in ostio fluminis perierit, tenetur primus navicularius? Labeo, si culpa caret, non teneri ait: ceterum si vel invito domino fecit vel quo non debuit tempore aut si minus idoneae navi, tunc ex locato agendum.

\section{TRADUÇÃO NOSSA:}

Se um barqueiro tiver recebido uma carga para transportar até Minturnas e, não podendo entrar no rio minturnense com aquele barco, tiver trasladado as mercadorias para um outro barco, e esse barco houver naufragado na desembocadura do rio, responderá o primeiro barqueiro ? Labeão diz que não responde, se não teve culpa: de resto, se o fez contra a vontade do dono, ou em um tempo no qual não deveria fazê-lo, ou se num barco menos adequado, então deve-se acioná-lo com base no contrato de locatio-conductio. ${ }^{33}$

\footnotetext{
que quem aluga bestas de carga muitas vezes as põc a conduzir por outras pessoas, conclui quc, para os autores desse fragmento, o locatário cm tais casos responde pelos atos dessas pessoas como pclos scus próprios.

33. É verdadc que o texto dá a impressão de estar truncado, c Knütcl (SZ 100 [1983], p. 415, nt. 315) julga que falta um verbo após o "aut si...", cmbora possa ser simplesmente um caso de zeugma com o "ill fecit" mencionado anteriormente, o ablativo ai expressando um adjunto adverbial de instrumento ou de mcio. Faz sentido sc cntendermos o "id fecit" como "merces vexit". Em nossa tradução do fragmento adotamos cssa interpretação.
} 
Quando Ulpiano nos diz que o barqueiro "in aliam navem merces transtulerit" na verdade não está apenas querendo dizer que as mercadorias foram transportadas em outro barco pelo mesmo conductor, mas sim que ele próprio locou, por sua vez, os serviços de um segundo barqueiro, para que este realizasse o transporte em seu lugar. Isso se infere com segurança com base na pergunta proposta ("tenetur primus navicularius?"), indicando com clareza que havia um segundo navicularius envolvido na história, ou seja, uma pessoa livre e independente, vinculada ao primeiro barqueiro apenas por um vínculo contratual.

Labeão (e com ele Ulpiano) primeiramente exclui a responsabilidade do primeiro navicularius se ele "culpa caret" i.e. se não teve culpa. Uma semelhante afirmação do jurisconsulto já descarta de antemão a idéia de uma simples Gefahrtragung ou Versicherungshaftung - em suma: simples responsabilidade objetiva - por parte do conductor. Entretanto, nenhum dos exemplos dados a seguir por Labeão como exceção à regra da não responsabilização do conductor parece sugerir alguma culpa por parte do segundo navicularius. Diz ele que o primeiro barqueiro responde se trasladou a mercadoria "invito domino" (contra a vontade do proprietário) ou "quo non debuit tempore" (em tempo não devido, certamente do ponto de vista técnico da navegação, cf. com Paul. 31 ad ed. D. 6,1,16,1); o primeiro caso é flagrante violação dos deveres contratuais e uma ação ultra vires por parte do conductor, e o segundo se explica pela teoria clássica da culpa.

Resta o terceiro exemplo dado, "si minus idonea navi" MAYERMALY, ${ }^{34}$ diz que ai está contida a idéia de culpa in eligendo. Certamente está, mas Ulpiano diz que mal escolhida foi a navis, não o navicularius. Não há porque supor que isso indique a hipótese de o acidente ter sido causado por ato imputável ao segundo barqueiro, parecendo, antes, uma alusão à possibilidade de que a segunda nave escolhida também tivesse um calado muito alto, ou fosse de porte demasiado pequeno para o peso da carga, ou qualquer outra inadequação dessa mesma natureza.

É bem possivel, no entanto, que Labeão e Ulpiano pretendessem incluir no rol de possibilidades de responsabilidade do conductor também o caso em que o segundo barqueiro tivesse dado causa ao acidente por falha sua, mas o texto não dá indicação nenhuma disso, a não ser que o próprio conductor tivesse culpa no fato. Não se descarta, é natural, a hipótese de que nessa culpa se incluisse a culpa in eligendo, ao escolher um navicularius descuidado ou inepto, que pusesse a nave a pique por ter 
manejado canhestramente o leme; mas essa conclusão não decorre diretamente das palavras do texto e ficam no campo da conjetura.

Embora se refira a um instituto completamente diverso, o seguinte trecho de Paulo é bastante adequado para comparar com D.19,2,13,1:

\section{D.3,5,20(21),3 Paul. 9 ad ed.}

Mandatu tuo negotia mea Lucius Titius gessit: quod is non recte gessit, tu mihi actione negotiorum gestorum teneris non in hoc tantum, ut actiones tuas praestes, sed etiam quod imprudenter eum elegeris, ut quidquid detrimenti neglegentia eius fecit, tu mihi praestes.

\section{TRADUÇÃO NOSSA:}

A mandado teu Lúcio Tício geriu os meus negócios: porque ele não geriu direito, tu te obrigas comigo pela ação de gestão de negócios; e não apenas de modo a que me cedas tuas ações, mas também - porque o escolheste imprudentemente - de modo que me repares todo e qualquer prejuizo que a negligência dele me causou.

Aqui, sim, parece-nos configurar-se um exemplo nítido de responsabilidade pelo fato de um terceiro (o mandatário Lúcio Tício). A ocorrência deste caso em uma esfera que, inquestionavelmente, exclui as figuras particularíssimas do receptum e da custodia (ou seja, na esfera da negotiorum gestio) é significativa, e não há tampouco razão para supor que essa responsabilidade seja simplesmente uma modalidade de Gefahrtragung ${ }^{35}$ ou Versicherungshaftung ${ }^{36}$ por parte do negotiorum gestor. Ou seja: ele responde por um ato culposo (ou doloso) do mandatário (diz Paulo: "quod is non recte gessit"), mas nada parece indicar que ele deva responder incondicionalmente por vis maior ou casus minor. Também é evidente que Lucius Titius é pessoa livre e sui iuris, atuando como preposto de $T u$ por força de uma relação contratual (mandato) existente entre eles.

Menos evidente é o fundamento jurídico desse dever de responder pelo mandatário. Paulo disse que Tu responde pelos atos de Lucius Titius “quod imprudenter eum elegeris" o que aparentemente significaria o reconhecimento de uma culpa in eligendo. No entretanto, o uso da conjunção quod sugere que Paulo não está apresentando uma hipótese ("se você o tiver escolhido imprudentemente"), mas antes

35. "Assunção do risco" Cf. nt. th 27 supra.

36. "Dever de garantia". Conforme a cxpressão cmpregada a csse propósito por Krückmann, Versicherungshaftung im römischen Recht, in SZ 63 (1943), pp. I ss. 
uma conclusão inelutável ("porque você o escolheu imprudentemente"). Isso corresponderia, na verdade, a uma responsabilidade objetiva do mandante na escolha do mandatário.

Os defensores de uma doutrina romana da culpa in eligendo, sobretudo os pandectistas, ${ }^{37}$ insistiam em tentar explicar o fragmento com base nessa idéia. Outros, no passado, (e.g. Krückmann) ${ }^{38}$ supunham tratar-se de uma mera presunção iuris et de iure de culpa, e portanto de uma responsabilidade subjetiva. Outra possível visão seria a de, por exemplo, De Robertis, ${ }^{39}$ que prefere considerar esse um caso de presunção iuris tantum de culpa in eligendo. Já Knütel ${ }^{40}$ prefere reinterpretar o sentido de quod, lembrando que não necessariamente é explicativo em latim, podendo ser traduzido por "was, das betrifft" ou "wenn" ou seja, com sentido hipotético ("naquilo que toca a" "no caso de" "se"), excluindo assim a hipótese de culpa presumida..

Somos da opinião que, se Paulo pretendesse atribuir a $T u$ uma responsabilidade objetiva e sem culpa, ou um dever incondicional de garantia pelo bom êxito da gestio, teria ele dito isso com todas as letras. Se ele trouxe à discussão a culpa pessoal do negotiorum gestor - real ou presumida foi porque ele não pretendeu afastar a solução desse caso do campo da responsabilidade por culpa. O "quod is non recte gessit" revela claramente que se o dano tiver sido causado sem culpa de Lucuis Titius, não há falar em responsabilidade.

Por outro lado, o "quod imprudenter eum elegeris" indica que o fundamento para a responsabilidade do negitiorum gestor é uma conduta culposa pessoal sua. Pode-se indagar a quem cabia o ônus da prova: a Ego ou a Tu (havendo, nessa última hipótese, uma presunção iuris tantum a favor de Ego, embora Paulo permaneça silente a esse respeito), mas não há como inferir do texto que pudesse haver nesse caso uma culpa presumida iuris et de iure. Essa é uma interpretação possível, mas não

37. É o caso de Brinz, para quem Paulo fala de uma culpa in eligendo provada ipso facto c ex post facto .(Pandekten, II, \$270, p. 278, nt. 7). Isso equivalc a dizcr, portanto, que o simples fato de Lucius Titius ter agido mal já cstaria sendo tomado como prova suficiente de que $T u$ foi pouco prudente na cscolha. Mas nessc caso, como muito bcm argumenta Krückmann (Custodia, in SZ 64 [1944], p. 49), a cventual alusão a uma culpa in eligenclo não deve ser lcvada a sćrio, scndo muito mais uma responsabilidade incondicional pela culpa de tercciros - embora não uma responsabilidade puramente objetiva pela ocorrência do dano $\mathrm{cm}$ si mcsmo, pois também cssc autor concorda $\mathrm{cm}$ quc a culpa de Lucius Titius ć apresentada como conditio sine qua non para a responsabilização de Tu.

38. SZ 63 (1943), p. 49.

39. La responsabilità... (cit. nt. Ih 26 supra), v. 2, p. 819 , nt. 39 .

40. SZ 100 (1983), p. 346. 
respaldada em fato algum; o uso de quod em lugar de si ou quando é indício insuficiente, conforme já discutimos, e seria distorcer o pensamento do jurisconsulto pretender extrair essa ilação sem maiores evidências. À falta de argumentos que nos convençam do contrário, parece-nos ajuizado admitir que Paulo disse exatamente o que pretendeu dizer: que $T u$ responde pelo prejuízo porque foi imprudente ao nomear Lucius Titius seu mandatário face aos negócios de Ego. O fundamento da responsabildade é, portanto, culpa própria do mandatário, tal como em D.19,2,13,1:

Do que foi discutido supra podemos concluir alguns pontos, que enumeramos a seguir:

1) Parece inegável, dos textos examinados, que não repugnava aos juristas romanos admitir, ao menos em certos casos, que uma pessoa respondesse por atos de terceiros, mesmo que não fossem seus escravos nem pessoas submetidas à sua potestas.

2) A incidência dessa responsabilidade por terceiros parece ser localizada e restrita a certas circunstâncias ou certos institutos, não se manifestando como regra global. Ao que parece, ocorria sobretudo em atividades cujo grande risco (como nos contratos de transporte) ou nos casos em que o devedor confiou a um terceiro, por conta e risco próprios, coisas ou serviços que a ele pessoalmente haviam sido destinados - ainda que não se trate de contratos realizados intuitu personae, que só pudessem ser cumpridos pessoalmente por ele. Tais situações justificariam um agravamento na responsabilidade do devedor, estendida até aos atos de seus auxiliares livres e sui iuris - uma responsabilidade da qual ele não poderia escapar pela noxalis deditio ou pela limitação a uma actio adiecticiae qualitatis, devendo, antes, responder in solidum.

3) É espinhoso tentar elucidar os critérios para essa atribuição de responsabilidade. Em alguns casos, como em Ulp. 32 ad ed. D.19,2,13,1 e Paul. 9 ad ed. D.3,5,20,3, tudo indica que o devedor esteja respondendo com base em culpa própria sua - que podemos admitir ser culpa in eligendo, sem com isso afirmar que tivesse sido erigida em doutrina geral no direito clássico, o que como sabemos é questão controversa; em outros, como Gai 10 ad ed. D.19,2,25,7 e Alfen. 7 dig. D.19,2,30,2, parece, ao contrário, que o devedor responde diretamente pela falta cometida por terceiros, ainda que ele próprio estivesse isento de toda culpa.

Um fundamento para essas decisões díspares não é fornecido pelas fontes. Podemos considerar, porém, um detalhe que pode ser significativo. Nos dois primeiros fragmentos mencionados no parágrafo anterior temos uma mesma situação: alguém é 
encarregado, por força de um contrato (locatio conductio operis faciendae, mandatum), a realizar uma determinada tarefa; no cumprimento da tarefa, o devedor constata a necessidade de delegar suas funções a um terceiro, por meio de um subcontrato entre eles, fazendo-se destarte substituir por esse terceiro no cumprimento da prestação. Já nos dois outros casos o dano é causado por meros auxiliares do devedor, que realizam a tarefa conjuntamente com ele ou por ordem dele, mas sem a autonomia de um empreiteiro ou mandatário.

Essa circunstância já havia levado, por exemplo, Kunkel ${ }^{41}$ a conjeturar que, ao menos nesses contratos, o devedor respondia pela culpa de seus auxiliares ("Gehilfe") na mesma medida em que respondia por sua culpa própria, mas só seria responsabilizado pela falta de terceiros a quem delegasse tarefas ("Substituten") na medida em que lhe fosse imputada alguma culpa pessoal no ato de lhes fazer essa delegação (o que não compreende apenas culpa in eligendo na seleção desses "substitutos", mas também na escolha do equipamento adequado (como o barco que subia o rio minturnense em D.19,2,13,1) ou o tempo adequado para realizá-la (como no próprio caso do rio minturnense ou no caso análogo de Paul. 31 ad ed. D. 6,1,16,1).

É uma idéia deveras interessante, e merecedora de toda a atenção. $O$ caso do agrimensor em Paul. 25 ad ed. D.11,6,2,1 pareceria desmentir essa teoria. Lembremos, porém, a excepcionalidade do instituto, a gravidade dever do agrimensor (solenizada na renuntiatio), além da circunstância especial de ser uma obrigação tutelada pelo edito, prevista unicamente a responsabilidade por dolo. Tudo isso pode ter motivado o jurisconsulto a ter emanado uma decisão extravagante.

São Paulo, fevereiro de 2001.

41. Jörs/Kunkcl, Römisches Privatrecht, Bcrlin/Göttingcn/Hcidelberg, Springer Verlag, 1943, p. 239, $\$ 149$. 